\title{
NEW OMCVD PRECURSORS FOR SELECTIVE COPPER METALLIZATION
}

\author{
J.A.T. NORMAN, B.A. MURATORE, P.N. DYER, D.A. ROBERTS and \\ A.K. HOCHBERG \\ SCHUMACHER, 1969 Palomar Oaks Way, Carlsbad, California, U.S.A
}

\begin{abstract}
Due to its excellent electrical conductivity and high electromigration resistance, copper is widely predicted to be the interconnect metal of the future for electronic microdevices. This presentation focusses upon the synthesis of a new series of volatile liquid $\mathrm{Cu}^{+1}$ complexes which are shown to be suitable for the deposition of pure, adherent and highly conducting copper films by CVD. Selective depositions onto metallic versus insulating dielectric substrates are achieved between 120 to $420^{\circ} \mathrm{C}$ with growth rates in excess of $100 \mathrm{~nm} / \mathrm{min}$ and grain sizes as low as 0.1 microns. In addition, a novel complementary copper etching process is discussed that is chemically compatible with the copper CVD chemistry.
\end{abstract}

\section{Introduction}

As the design rules for integrated circuits shrink below one half micron the maximum operating frequency of a microprocessor becomes steadily more controlled by the electrical conductivity of its device interconnects1. Due to this fundamental limitation, copper is poised to become the next interconnect metal of choice since it is an excellent electrical conductor which in addition offers high electromigration resistance 1-3. To achieve the effective filling and conformal coverage of high aspect ratio sub-halfmicron surface features, CVD rather PVD copper processes are being aggressively sought. Especially desirable are low temperature $\left(\angle 200^{\circ} \mathrm{C}\right)$ site selective copper CVD processes. This paper discusses the results of a basic research program focussed upon the molecular design and synthesis of new volatile liquid organometallic copper complexes that fullfill these requirements. The chemistry of this metallization process is believed to proceed via a novel CVD mechanism in which the precursor molecules simply rearrange, rather than decompose, to cleanly release copper metal by a disproportionation reaction. As a complement to the CVD metallization, a selective dry etching process for copper is also discussed that is chemically related to and compatible with the copper CVD chemistry.

\section{Results and Discussion}

\section{a. Precursor design}

The molecular formula of the parent complex of this new series of copper precursors, i.e. $\mathrm{Cu}+1$ (hexafluoroacetylacetonate)trimethylvinylsilane, [Cu+1(hfac)TMVS], is shown below in Figure 1. Its Clausius-Clapeyron vapor pressure/temperature plot is shown in Figure 2. 


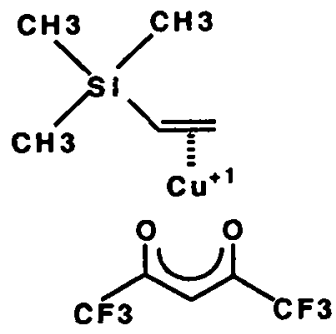

Figure 1. $\left[\mathrm{Cu}^{+1}(\mathrm{hfac}) \mathrm{TMVS}\right]$

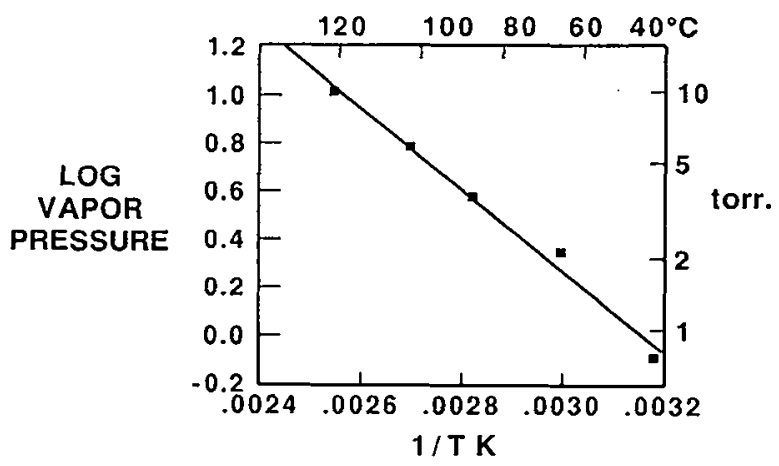

Figure 2. $\left[\mathrm{Cu}^{+1}(\mathrm{hfac}) \mathrm{TMVS}\right]$ Vapor Pressure

This new precursor is a pale yellow distillable low viscosity organometallic liquid. At the molecular level, this precursor is constructed of two key components. These are $\mathrm{Cu}+1$ hexafluoroacetylacetonate (i.e. $\mathrm{Cu}^{+1} \mathrm{hfac}$ ) and trimethylvinylsilane (i.e. TMVS). The role of the TMVS is to stabilize the copper+1 oxidation state while the complex is either a liquid or gas under moderate temperature conditions. Under CVD conditions at more elevated temperatures $\left(>130^{\circ} \mathrm{C}\right)$ the TMVS can be made to dissociate from the complex thereby generating unstable $\mathrm{Cu}+1 \mathrm{hfac}$ species which then disproportionate to yield copper metal and volatile $\mathrm{Cu}+2(\mathrm{hfac})_{2}$. This entails an electron transfering from one copper+1 atom to another. The atom releasing the electron becomes oxidized to copper +2 while the atom receiving the electron is reduced to copper metal. In this overall sequence the TMVS is liberated as a chemically unchanged molecule and the (hfac) anions are simply rearranged to coordinate to the copper +2 atom. Therefore, the net result is a very clean metallization process that requires no added reagents to effect deposition. This chemistry is shown in the equation below.

$$
2 \mathrm{Cu}+1(\mathrm{hfac}) \mathrm{TMVS}_{(\mathrm{g})} \cdots \mathrm{Cu}_{(\mathrm{s})}^{\circ}+\mathrm{Cu}+2(\mathrm{hfac}) 2(\mathrm{~g})+2 \mathrm{TMVS}_{(\mathrm{g})}
$$

Conductors rather than insulators appear to catalyse the above reaction which is probably related to the need for electron transfer to occur. We therefore observe selective deposition of copper onto metallic surfaces. Since it is necessary to provide a copper impervious barrier film such as tantalum, titanium nitride or tungsten between a copper interconnect and its silicon substrate ${ }^{4}$, this selective deposition permits the direct growth of copper onto these surfaces. It was also discovered that the above chemistry of deposition could be reversed, that is copper metal could be etched away as a volatile copper ${ }^{+1}$ complex by a gaseous mixture of $\mathrm{Cu}^{+2}(\mathrm{hfac})_{2}$ and TMVS. This is discussed in greater detail in section $\mathrm{c}$.

\section{b. Deposition of copper}

In the CVD evaluation of $\mathrm{Cu}^{+1}$ (hfac)TMVS we principally investigated the areas of selectivity, purity and resistivity, growth rate and grain size.

The selectivity of deposition from $\mathrm{Cu}^{+1}(\mathrm{hfac}) \mathrm{TMVS}$ was demonstrated in two different ways. In one set of experiments a metallized silicon coupon, for example tungsten on silicon, was set alongside another silicon coupon bearing a silicon oxide surface and the two samples were simultaneously exposed to the same CVD conditions for the deposition of copper. In each case a strong selectivity towards the metallic 
surface was observed. In the other set of experiments, selectivity was demonstrated by exposing a tungsten/silicon oxide "patterned wafer" or FLTC (Fine Line Test Circuit) to copper CVD conditions. A cross section of the FLTC used is shown below diagramatically in Figure 3.

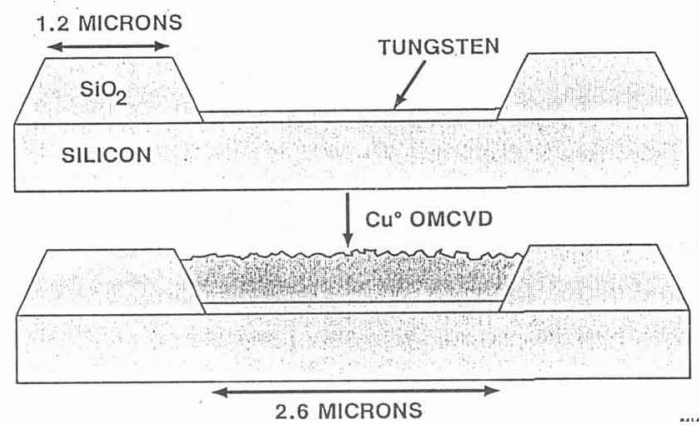

Figure 3. $\mathrm{W} / \mathrm{SiO}_{2}$ FLTC Cross Section

In these experiments it was observed that copper deposition occured only on the metallic surfaces and not on the silicon oxide. A typical result would be complete metallization of the the tungsten with less than 1 grain of copper observed on the silicon oxide surface per $10^{4}$ (microns) ${ }^{2}$ of FLTC area. Micrographs of copper deposited FLTCs are shown below in Figures 4 and 5. In Figure 5 it is striking how the selectivity persists even when the copper film has risen more than twice higher than the trench is deep. Since the tungsten diffusion barrier of the FLTC is applied by a WF 6 CVD process, the deposition of a copper interconnect by this process is an example of an all CVD, selective, selfaligned metallization. All of the above selective depositions were shown to be effective across a broad temperature range of $120-420^{\circ} \mathrm{C}$ with growth rates in excess of $100 \mathrm{~nm} / \mathrm{min}$ at a pressure of $100 \mathrm{mtorr}$.
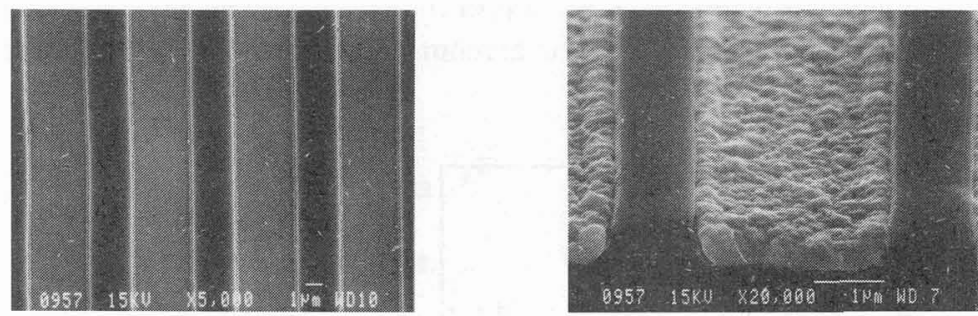

Figure 4. Selective Copper Deposition onto $\mathrm{W} / \mathrm{SiO}_{2}$ FLTC
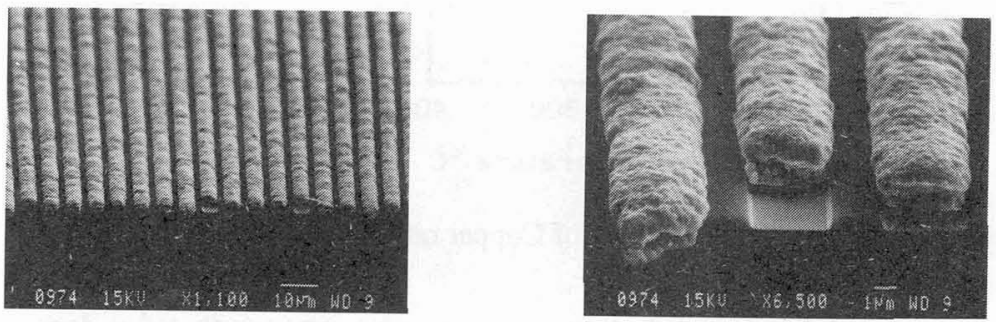

Figure 5. Additional Selective Copper Deposition on $\mathrm{W} / \mathrm{SiO}_{2} \mathrm{FLTC}$ 
A summary of all the selective depositions is shown in Table 1. The narrow temperature range indicated for titanium nitride, tantalum, aluminum and platinum silicide is not a reflection of the only temperatures at which selective deposition could be achieved, they are the only temperatures that were evaluated.

Table 1

Selective Depositions

Run Conditions:

Source Temperature $=40^{\circ} \mathrm{C}, \mathrm{OMCVD}$ Pressure $=100 \mathrm{mtorr}$

$\begin{array}{lcc}\text { Substrates } & \text { Selectivity } & \text { Temp. Range Studied } \\ {\mathrm{W} \mathrm{vs} \mathrm{SiO}_{2}}_{\mathrm{TiN} \text { vs } \mathrm{SiO}_{2}} & \mathrm{~W} & 120-420^{\circ} \mathrm{C} \\ \mathrm{Ta} \text { vs } \mathrm{SiO}_{2} & \mathrm{TiN} & 150-180^{\circ} \mathrm{C} \\ \mathrm{Al} \text { vs } \mathrm{SiO}_{2} & \mathrm{Ta} & 180^{\circ} \mathrm{C} \\ \mathrm{PtSi} \text { vs } \mathrm{SiO}_{2} & \mathrm{Al} & 150^{\circ} \mathrm{C} \\ & \mathrm{PtSi} & 150-200^{\circ} \mathrm{C}\end{array}$

$*<10$ grains copper $/ 10^{4} \mu \mathrm{m}^{2}$ on $\mathrm{SiO}_{2}$, films up to $3 \mu \mathrm{m}$ thick

The composition of the deposited copper was determined via Auger electron spectroscopy depth profiling and in every case only high purity metal was found with carbon, fluorine and oxygen at lower than detectable limits. Room temperature resistance measurements of 1.36 to 1.95 microns thick copper films grown onto a silicon dioxide substrate resulted in resistivities on the order of 2.0 microohm cm. This is in good agreement with previously reported CVD copper films 5-8 and is encouragingly close to the reported bulk resistivity of copper at 1.7 microohm $\mathrm{cm}$ at room temperature. The results are shown below in Figure 6.

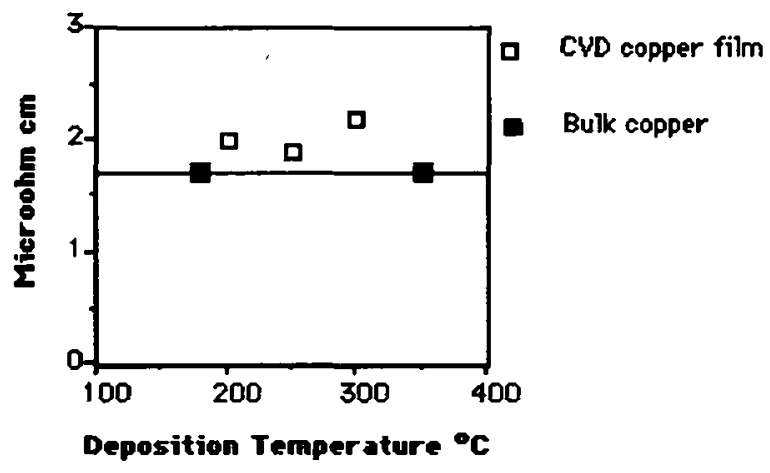

Figure 6. Resistivity of Copper on $\mathrm{SiO}_{2}$

To determine the sensitivity of growth rate to temperature, experiments were conducted to deposit copper onto TiN using $\mathrm{Cu}+1$ (hfac)TMVS between $150-350^{\circ} \mathrm{C}$ using argon as a carrier gas. Argon was bubbled at flow rates of 9.2 and $22.7 \mathrm{sccm}$ through the liquid precursor at 10 torr with the source temperature set at 40 or $50^{\circ} \mathrm{C}$. Thus the transport rate of complex through the reactor was steadily increased. As the 
Armenius plot shown in Figure 7 indicates, the sensitivity of deposition rate to substrate temperature remained basically unchanged throughout these runs. The overall activation energy for this process is approx. $2 \mathrm{kcal} / \mathrm{mole}$. This is a very low value since typical activation energies for copper and other metallizations using different precursors fall within the range of $20-50 \mathrm{kcals} / \mathrm{mole} .9-11$ One possible explanation for this is that the system is still mass transfer limited or "starved" of precursor. A further increase in the throughput of complex could result in a steeper gradient than that observed below. However, one might anticipate that a disproportionation route similar to the one proposed here would have a somewhat lower activation energy than those associated with more traditional thermolytic mechanisms. This would be advantageous from a processing perspective since wafer temperature uniformity would present less of a problem in terms of achieving a uniform thickness of metal film.

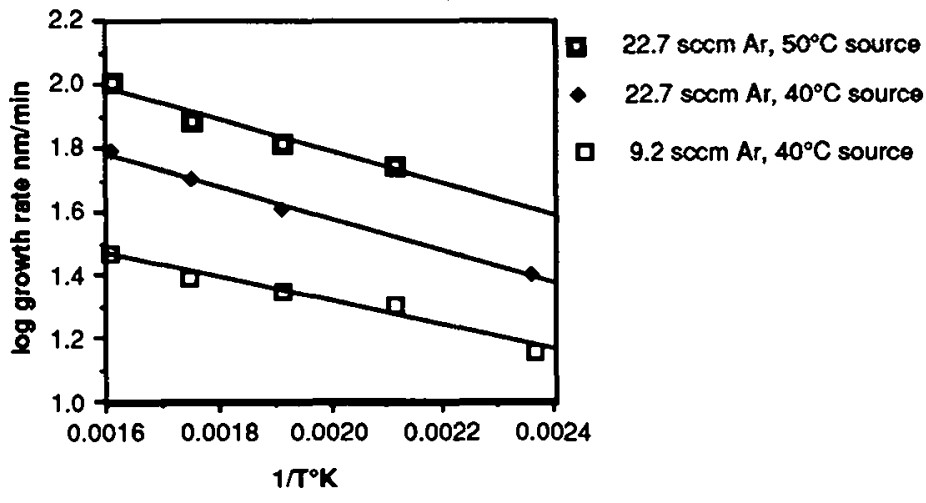

Figure 7. Copper Deposition onto TiN at 10 Torr in Ar

Grain sizes of the deposited copper films were found to vary fairly linearly with temperature, higher temperatures yielding larger grains. In Figure 8 the grain sizes of copper deposited onto tungsten FLTC substrates are shown to be consistently smaller than those deposited onto TiN for a given temperature. However, the copper films on TiN are approximately five times the thickness of those on tungsten, presumably due to a higher level of mass transport of precursor through the reactor via the argon carrier gas. As there is no detectable initiation period for copper growing upon either of these substrates, once a film starts to form it is really copper growing upon copper. Therefore, assuming that the growing film has no "memory" of the identity of its underlying substrate, grain size is dependent upon the time that a film has been growing in addition to the deposition temperature. Since grain sizes as low a 0.1 microns are observed, the potential for sub-halfmicron interconnect fabrication has been demonstrated.

\section{c. Selective dry etching of copper}

Metallization processes typically require a complementary metal etch technique so that excess deposited metal can be removed in a post-deposition clean up. As described earlier, the $\mathrm{Cu}+1$ (hfac)TMVS complex deposits copper metal via a disproportionation. During the course of our studies we also discovered that this reaction could be reversed under certain conditions such that copper metal could be etched by a 


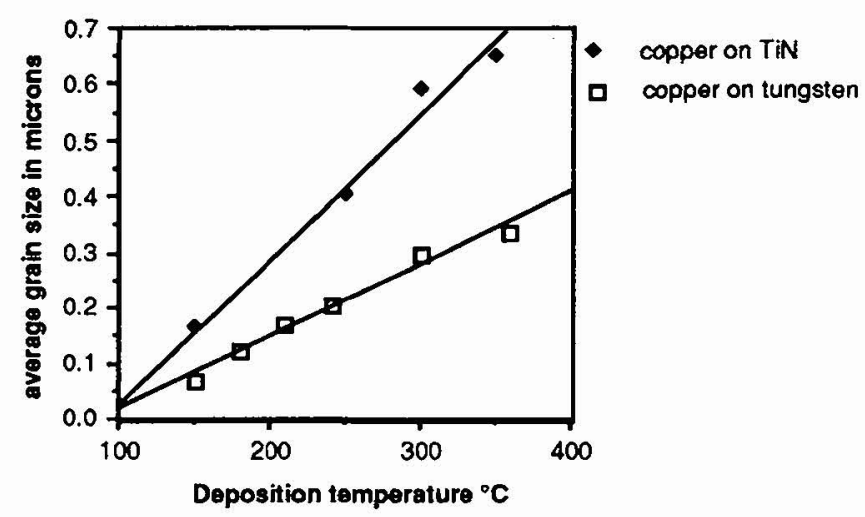

Figure 8. Copper Grain Size vs. Temp. for W and TiN

mixture of $\mathrm{Cu}+2(\mathrm{hfac}) 2$ and TMVS, both in the vapor phase. Thus copper metal is converted into a volatile copper +1 complex and is evaporated away from the solid metal surface. Importantly, this process is selective for copper metal. The effectiveness of this etching mixture was demonstrated as shown in Figure 9 by flowing it over a test coupon ( $1000 \AA$ magnetron sputtered $\mathrm{Cu}^{\circ}$ on $1200 \AA \mathrm{Ta}$ on $5000 \AA \mathrm{SiO}_{2}$ on $\mathrm{Si}$ ) heated to $140^{\circ} \mathrm{C}$. The coupon was partly masked with polyimide tape to protect some areas from the etch and hence provide a reference point by which to gauge the effectiveness of the process. After 20 mins the exposed copper surface was found to be etched down to the tantalum. This was determined by stylus profilometry and by inspection using a scanning electron microscope.

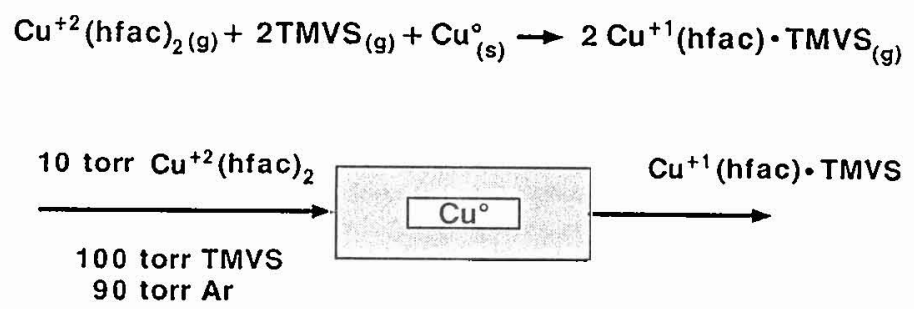

Figure 9. Copper Etch, Reverse of Deposition

\section{Experimental}

The depositions were carried out as follows:

Vapors of pure $\mathrm{Cu}+1$ (hfac)TMVS were fed into a four-way vacuum cross of a cold wall CVD reactor by means of a dynamic vacuum of approx $10^{-1}$ torr where they contacted a resistively heated stainless steel susceptor bearing the sample coupons set at the predetermined deposition temperature. The actual temperature of a given sample was measured via a thermocouple contacting the underside of the test coupon. Each run would start by first loading the test coupons onto the susceptor under a purge of nitrogen and evacuating the reactor to $10^{-6}$ torr for 30 minutes whilst heating the susceptor to the desired 
run temperature. A liquid nitrogen cooling trap positioned upstream of the pump condensed out all the volatiles from the CVD process. During these runs unreacted copper+1 complex was observed in the trap as a yellow green oil along with dark blue crystals of $\mathrm{Cu}+2(\mathrm{hfac})_{2}$ as a product of disproportionation. The source vessel bearing the complex was in a water bath heated to $40^{\circ} \mathrm{C}$ and the delivery lines from it to the susceptor and the reactor walls were both heat traced to $60^{\circ} \mathrm{C}$. For the runs using the FLTCs selective deposition of copper was observed between $120^{\circ} \mathrm{C}$ and $500^{\circ} \mathrm{C}$ (if in the latter case the run time was restricted to less than one minute, after which blanket deposition occured). Alternatively, the $\mathrm{Cu}+1$ (hfac)TMVS precursor could be run through the reactor by bubbling argon gas through it at an overall reactor pressure of 10 to 20 torr. In this way copper was selectively deposited onto the tungsten of an FLTC coupon at $150^{\circ} \mathrm{C}$ and blanket deposited onto TiN between 150 and $350^{\circ} \mathrm{C}$. These latter runs were conducted with source temperatures up to $50^{\circ} \mathrm{C}$. Grain sizes of the deposited copper films were determined by measurement from micrographs obtained from an electron microscope. Film purity was determined by Auger electron spectroscopy depth profiling using a PHI 560 ESCA/SAM spectrometer with the electron gun set at $5 \mathrm{KeV}, 0.5$ microamps; ion gun at $4 \mathrm{KeV}, 3 \times 3 \mathrm{~mm}$ raster.

The etching of copper was accomplished as follows:

A stream of argon gas at a flow rate of $122 \mathrm{sccm}$ and a pressure of 200 torr was bubbled through a sample of $\mathrm{Cu}^{+2}(\mathrm{hfac})_{2}\left(\right.$ molten at $100^{\circ} \mathrm{C}$ ) to yield a saturated vapor of the copper complex. A separate stream of argon at a flow rate of $122 \mathrm{sccm}$ and 200 torr pressure was bubbled through a sample of TMVS at $0^{\circ} \mathrm{C}$ to yield a saturated vapor of TMVS. These two gas streams were then mixed to yield an atmosphere composed of approximately 100 torr TMVS, 10 torr $\mathrm{Cu}+2(\mathrm{hfac})_{2}$ and 90 torr argon. This gaseous mixture was then passed over a copper covered surface heated to $140^{\circ} \mathrm{C}$ for 20 minutes resulting in complete etching of the copper surface. In separate experiments identical copper surfaces at $140^{\circ} \mathrm{C}$ were exposed to either pure $\mathrm{Cu}+2(\mathrm{hfac}) 2$ vapor $(10$ torr copper complex in argon at a total pressure of 200 torr), or to pure TMVS vapor (100 torr TMVS in argon at a total pressure of 200 torr) at flow rates of $122 \mathrm{sccm}$ in each case. Neither of these runs resulted in any observable etching of copper. Thus the necessity of requiring both components in unison to accomplish the etch was demonstated.

Resistivity was measured using a four point probe at room temperature at current values of $1,3,5,10$, and $50 \mathrm{~mA}$. The synthesis of the $\mathrm{Cu}+1(\mathrm{hfac}) \mathrm{TMVS}$ complex was accomplished using a reported procedure. 12

\section{Conclusions}

The volatile, liquid, OMCVD precursor, $\mathrm{Cu}+1$ (hfac)TMVS, has been shown to deposit fine grained, low resistivity copper selectively onto diffusion barrier and conducting surfaces such as TiN, W, Ta, PtSi, and Al. The selectivity was retained over a wide temperature range of 120 to $420^{\circ} \mathrm{C}$ and at pressures of 0.1 to 40 torr, and no copper was found on adjacent $\mathrm{SiO}_{2}$ surfaces. Deposition rates in excess of 100 $\mathrm{nm} / \mathrm{min}$ were observed.

The deposition process occurs via a disproportionation reaction, which does not release any corrosive or contaminating by-products into the system. The reverse reaction has been demonstrated to be a complementary, selective, non-corrosive dry etch for copper.

This novel precursor and deposition process allows copper CVD metallization to be carried out selectively at sub-micron geometries and at low temperatures. 


\section{References}

1. PAI, P. L., TING, C. H., IEEE Device Letters, 10 (1989) 423.

2. HU, C. K., CHANG, S., SMALL, M. B., and LEWIS, J. E., V-MIC Proceedings, 3 (1986) 181.

3. HOSHINO, K., YAGI, H., TSUCHIKAWA, H., V-MIC Proceedings, 6 (1989) 226.

4. CHAMBERLAIN, M. B., Thin Solid Films, 91 (1982) 155.

5. HAMPDEN-SMITH, M J., KODAS, T. T., PAFFETT, M., FARR, J. D., AND SHIN, H. K. Chem. Mater., 2 (1990) 636.

6. TEMPLE, D. AND REISMAN, A., J. Electrochem. Soc. 136 (1989) 3525.

7. FINE, S. M., NORMAN, J. A. T., and DYER, P. N., MRS Symposium Proc., 204 (1990) 415.

8. KALOYEROS, A. E., FENG, A., GARHART, J., BROOKS, K. C., and LUEHRS, F., J. Electron. Mater., 19 (1990) 271.

9. BEACH, D. B., LEGOUES, F. K., HU, C. K., Chem. Mater. 2 (1990) 216.

10. CACOURIS, T., SCARMOZZINO, R., OSGOOD, R. M., JR., VMIC Proceedings, 7 (1990) 268.

11. DUBOIS, L., Schumacher Dielectrics and CVD Metallization Symposium Proc., 2 (1989) IX-7.

12. U.S. Patent Application, February 1991. 